\title{
Interaction between Lymphocytes and Platelets in the Synthesis of Prostacyclin
}

Kenneth K. Wu, Audrey C. Papp, Charles E. Manner, and Elizabeth R. Hall

Department of Internal Medicine, Division of Hematology and Oncology,

University of Texas Medical School at Houston, Houston, Texas 77030

\begin{abstract}
To test the hypothesis that prostacyclin $\left(\mathrm{PGI}_{2}\right)$ is formed via a biochemical interaction between platelets and lymphocytes, we measured eicosanoids by high performance liquid chromatography (HPLC) and radioimmunoassay (RIA). A distinct 6keto-prostaglandin $F_{1 \alpha}\left(6 K_{P G F}\right)$ peak was noted when $\left[{ }^{14} \mathrm{C}\right]$ arachidonic acid $\left(\left[{ }^{14} \mathrm{C}\right] \mathrm{AA}\right)$ was added to the mixed cell preparations which was increased by pretreating platelets with 1-benzylimidazole (1-BI). Lymphocytes prelabeled with $\left[{ }^{14} \mathrm{C} A \mathrm{AA}\right.$ failed to form $6 \mathrm{KPGF}_{1 \alpha}$ when stimulated with phytohemagglutinin (PHA) or ionophore A23187. When the prelabeled platelets were suspended together with aspirin-treated lymphocytes and stimulated with ionophore, thrombin, or collagen, a 6KPGF peak was detected and enhanced by $1-B I$. These results were supported by quantifying the 6KPGF ${ }_{1 \alpha}$ content in the HPLCpurified fraction by RIA. Adding prostaglandin $\mathrm{H}_{2}\left(\mathrm{PGH}_{2}\right)$ directly to lymphocytes led to $\mathbf{K K P G F}_{1 \alpha}$ production. Platelet aggregation and release were inhibited by lymphocytes in a doserelated manner. We conclude that lymphocytes possess $\mathbf{P G \mathbf { I } _ { 2 }}$ synthase activity which is capable of converting platelet-derived $\mathbf{P G H}_{2}$ into $\mathbf{P G I}_{2}$. PGI 2 formed is sufficient to inhibit platelet function.
\end{abstract}

\section{Introduction}

Human lymphocytes are capable of taking up arachidonic acid $(\mathrm{AA})^{1}$ and incorporating it into their phospholipids, yet they appear to possess minimal ability to convert that arachidonate into biologically active metabolites $(1,2)$. For example, Parker et al. detected the production of only small quantities of thromboxane $\mathrm{B}_{2}$ (TXB $\mathrm{TX}_{2}$, 5-hydroxyeicosatetraenoic acid (5-HETE),

This paper was presented at the annual meeting of the American Society for Clinical Investigation, 6 May 1985, and published as an abstract (1985, Clin. Res., 33:552A).

Address correspondence to Dr. Kenneth $\mathrm{K}$. Wu, Division of Hematology and Oncology, University of Texas Medical School, 6431 Fannin, Houston, TX 77030.

Received for publication 5 May 1986 and in revised form 13 January 1987.

1. Abbreviations used in this paper: AA, arachidonic acid; 1-BI, 1-benzylimidazole; HETE, hydroxyeicosatetraenoic acid; HHT, 12-hydroxyheptadecatrienoic acid; $6 \mathrm{KPGF}_{1 \alpha}$, 6-keto-prostaglandin $\mathrm{F}_{1 \alpha}$; PHA, phytohemagglutinin; PPP, platelet-poor plasma; PRP, platelet-rich plasma; PG, prostaglandin; $\mathrm{PGI}_{2}$, prostacyclin; TX, thromboxane.

J. Clin. Invest.

(c) The American Society for Clinical Investigation, Inc.

$0021-9738 / 87 / 06 / 1601 / 06 \$ 1.00$

Volume 79, June 1987, 1601-1606 and 12-HETE upon treating lymphocytes with phytohemagglutinin (PHA) (1). These metabolites were thought to be due to contamination of the lymphocyte preparation with platelets and neutrophils. Goldyne and Stobo observed that T lymphocytes prelabeled with $\left[{ }^{14} \mathrm{C}\right] \mathrm{AA}$ failed to synthesize eicosanoids although they did release free $\left[{ }^{14} \mathrm{C}\right] \mathrm{AA}(2)$. Hence, lymphocytes probably contain little or no cyclooxygenase activity to metabolize AA into active products such as $\mathrm{TXA}_{2}$ or prostacyclin $\left(\mathrm{PGI}_{2}\right)$.

Recent data have shown that the serum content of 6-ketoprostaglandin $F_{1 \alpha}\left(6 \mathrm{KPGF}_{1 \alpha}\right)$ is significantly higher than that of plasma $(3,4)$. This difference must be due to $\mathrm{PGI}_{2}$ synthesis by blood cells stimulated during the coagulation process. However, the identity of the cells responsible for $\mathrm{PGI}_{2}$ synthesis remains unknown. Since none of the isolated blood cell fractions produces $\mathrm{PGI}_{2}$ directly, one must consider the possibility that $\mathrm{PGI}_{2}$ is synthesized via a biochemical interaction between two different classes of cells. The purpose of this study was to test the hypothesis that, despite their lack of cyclooxygenase activity, blood lymphocytes possess $\mathbf{P G I}_{2}$ synthase activity which can convert platelet-derived (PG) endoperoxides into $\mathrm{PGI}_{2}$.

\section{Methods}

Materials. $1-\left[{ }^{14} \mathrm{C}\right] \mathrm{AA}(56 \mathrm{mCi} / \mathrm{mmol} \mathrm{sp}$ act) was obtained from New England Nuclear, Boston, MA. AA was obtained from Nu Chek Prep, Inc. (Elysian, MN). ADP and ionophore A23187 were obtained from Sigma Chemical Co., St. Louis, MO and collagen, from Hormon-Chemie, Munich, Germany. Thrombin was obtained from Parke, Davis \& Co., Detroit, MI; 1-benzylimidazole (1-BI), from Aldrich Chemical Co., Milwaukee, WI; and PHA, from Wellcome Diagnostic, Greenville, NC. Tritiated PG standards: $\mathrm{PGD}_{2}, \mathrm{PGE}_{2}, \mathrm{PGF}_{2 \alpha}, 6 \mathrm{KPGF}_{1 \alpha}, \mathrm{TXB}_{2}, 12$-hydroxyheptadecatrienoic acid (HHT), and 12-HETE, were purchased from New England Nuclear (Boston, MA).

$\mathrm{PGH}_{2}$ purification. $\mathrm{PGH}_{2}$ was prepared using $\mathrm{AA}$ and ram seminal vesicle microsomes, and the biosynthetically produced $\mathrm{PGH}_{2}$ was purified over a gravity flow silicic acid column and a cyanobonded phase HPLC self-packed column using a hexane-isopropanol gradient (5). The purified product is free from other eicosanoids as analyzed by gas chromatography-mass spectrometry. This ultrapurified $\mathrm{PGH}_{2}$ was active in inducing human platelet aggregation in low micromolar concentrations.

Preparation of lymphocytes and platelets. Both lymphocytes and platelets were isolated from venous blood of healthy human subjects. Lymphocyte suspensions were prepared by the Ficoll-Hypaque separation technique (6). Platelet and monocyte contaminations in the lymphocyte preparations were evaluated by light microscopic and scanning electron microscopic examinations. Scanning electron microscope work was performed by Dr. Bucana at University of Texas Cancer Center, Department of Cell Biology. The lymphocyte preparations were contaminated by a small percentage of platelets ranging from 3 to $15 \%$. Monocyte contamination was not detected by either microscopic examination. In some experiments, lymphocytes were inactivated by boiling at $100^{\circ} \mathrm{C}$ for 3 min. There was no apparent cell agglutination in the boiled lymphocyte preparation. Washed platelet suspensions were prepared according to the method described by Walsh (7). The final preparation was suspended in Tyrode's buffer containing $5 \mathrm{mM}$ calcium and $0.5 \mathrm{mg} / \mathrm{ml}$ human fibrinogen. Only freshly prepared cell suspensions were used. To obtain 
washed buffy coat preparations, venous blood was drawn into tubes containing $1 / 10 \mathrm{vol}$ of $3.8 \%$ sodium citrate, mixed and centrifuged at 3,000 $g$ for $20 \mathrm{~min}$. After removing plasma, the buffy-coat layer was carefully separated and washed three times in Tyrode's buffer and the final preparation was suspended in $2 \mathrm{ml}$ Tyrode's buffer that contained $5 \mathrm{mM}$ calcium.

Analysis of eicosanoids by HPLC. Three types of experiments were performed. In the first experiment $\left[{ }^{14} \mathrm{C}\right]$ arachidonate was added to lymphocyte suspensions $\left(10^{7}\right.$ cells $\left./ \mathrm{ml}\right)$ alone or with washed platelet suspensions $\left(3 \times 10^{8}\right.$ cells $\left./ \mathrm{ml}\right)$ in a platelet aggregometer cuvette and incubated at $37^{\circ} \mathrm{C}$ under constant stirring for $3 \mathrm{~min}$. In the second experiment washed platelets were prelabeled with $2 \mu \mathrm{M}\left[{ }^{14} \mathrm{C}\right]$ arachidonate at $37^{\circ} \mathrm{C}$ for $2 \mathrm{~h}$. The cells were washed twice to remove free radiolabeled arachidonate. Washed lymphocytes pretreated with $1 \mathrm{mM}$ aspirin were added to the labeled platelet preparation in an aggregometer cuvette for $1 \mathrm{~min}$ followed by addition of an agonist (ionophore A23187, thrombin, and collagen) for $3 \mathrm{~min}$. In the third experiment washed lymphocytes were prelabeled with $2 \mu \mathrm{M}\left[{ }^{14} \mathrm{C}\right]$ arachidonate at $37^{\circ} \mathrm{C}$ for $1 \mathrm{~h}$. Cells were washed twice to remove free radiolabeled arachidonate. Washed labeled lymphocytes were placed in an aggregometer cuvette and treated with ionophore or PHA for $3 \mathrm{~min}$. We performed all the incubation experiments for 3 min, because at this time period maximal eicosanoids were produced. The reaction was terminated by acidification to $\mathrm{pH} 3.0$. After the samples were neutralized, they were centrifuged and the supernatants were acidified to $\mathrm{pH}$ 4.0. Eicosanoids were extracted by using a Sep-Pak cartridge (Waters Associates, Millipore, Corp., Milford, MA) as previously described (8). Recovery for eicosanoids was 95\%.

The eicosanoids were analyzed by reverse phase HPLC (model Vista 5500 HPLC; Varian Associates, Inc., Palo Alto, CA). The prostanoids were separated using an isocratic solvent system of $35 \%$ acetonitrile in acidified water. After initial isocratic period, the solvent composition was changed to $50 \%$ acetonitrile in acidified water and ran for $10 \mathrm{~min}$ to elute HHT, leukotriene $B_{4}$, and HETEs. Next, a slight convex gradient was run from 50 to $75 \%$ acetonitrile for $8 \mathrm{~min}$ and then to $100 \%$ acetonitrile. Fractions were collected and the radioactivity was counted in a $\beta$-scintillation counter. Tritiated standards were used to determine the relative retention time of each eicosanoid.

RIA. Eicosanoids were separated by HPLC as described above and the fractions corresponding to $6 \mathrm{KPGF}_{1 \alpha}$ were pooled and assayed for $6 \mathrm{KPGF}_{1 \alpha}$ by a highly sensitive and specific RIA (9). To ascertain that an optimal amount of 12-HETE was produced at $3 \mathrm{~min}$ after addition of an agonist, we measured 12-HETE produced by platelet stimulated with $10 \mu \mathrm{M}$ AA at $1,3,5$, and 30 min by RIA (Seragen, Milford, MA). Our data indicated that the production reached plateau at $3 \mathrm{~min} .12$ HETE at these time points was $663,852,700$, and $878 \mathrm{ng} / \mathrm{ml}$, respectively.

Platelet aggregation. Platelet aggregation was measured by the turbidimetric method of Born (10) using a dual-channel aggregometer (Chrono-Log Corp., Havertown, PA). The procedure was modified to provide an appropriate control for reduced light transmission caused by the addition of lymphocyte preparation. For example, to determine the effect of lymphocytes on platelet aggregation, the platelet-rich plasma (PRP) cuvette in the aggregometer contained $0.2 \mathrm{ml}$ of lymphocyte preparations (varying concentrations) and $0.8 \mathrm{ml}$ of washed platelet suspensions $\left(3 \times 10^{8} / \mathrm{ml}\right)$, whereas the platelet-poor plasma (PPP) cuvette contained $0.2 \mathrm{ml}$ of lymphocyte preparation at an identical concentration and $0.8 \mathrm{ml}$ of the Tyrode's buffer used to suspend washed platelets. The mixtures were incubated at $37^{\circ} \mathrm{C}$ under constant stirring for $1 \mathrm{~min}$ before addition of the agonists: collagen $(2-15 \mu \mathrm{g} / \mathrm{ml})$, thrombin $(0.05-0.1 \mathrm{U} /$ $\mathrm{ml})$, AA (10-20 $\mu \mathrm{M})$, or buffer control. The extent of change in light transmission was continuously recorded for $5 \mathrm{~min}$. In all of the experiments performed using this modified procedure, the addition of lymphocytes to platelet suspensions without agonists caused minimal changes in light transmission. For the regular platelet aggregation experiments in which lymphocytes were not added, buffer alone was placed in the PPP cuvette. The concentration of each agonist was determined experimentally as the minimal concentration inducing maximal aggregation.
The $\mathrm{PGI}_{2}$-like activity was assayed by relating the percent inhibition of platelet aggregation of a tested sample to a calibration curve constructed by using varying concentrations of authentic $\mathbf{P G I}_{2}$ as previously described (11).

Platelet serotonin release. Platelet serotonin release was performed according to the method of Weiss et al. (12) with minor modification. In brief, $3 \times 10^{8}$ platelets/ml PRP was labeled with $2 \mu \mathrm{M}\left[{ }^{14} \mathrm{C}\right]$ serotonin at room temperature for $30 \mathrm{~min}$ and $20 \mu \mathrm{M}$ imipramine was then added. $0.45 \mathrm{ml}$ of labeled PRP was incubated with $0.05 \mathrm{ml}$ of lymphocytes or buffer in an aggregometer cuvette at $37^{\circ} \mathrm{C}$ for $6 \mathrm{~min}$ under constant stirring. The stirring bar was removed and the sample was centrifuged at $13,000 \mathrm{~g}$ for $1 \mathrm{~min}$ in an Eppendorf microfuge (Brinkmann Instruments, Inc., Westbury, NY). The radioactivity was determined in a $\beta$ scintillation counter.

\section{Results}

Fig. 1 shows a representative prostanoid profile analyzed by HPLC. A distinct $6 \mathrm{KPGF}_{1 \alpha}$ peak was noted when $10 \mu \mathrm{M}\left[{ }^{14} \mathrm{C}\right] \mathrm{AA}$ was added to a mixture of lymphocyte and platelet preparations. This peak was enhanced by pretreating platelets with a TX synthase inhibitor, $5 \mathrm{mM}$ 1-BI, but was abolished by pretreating platelets with $1 \mathrm{mM}$ aspirin. When $\left[{ }^{14} \mathrm{C}\right] \mathrm{AA}$ was added to a mixture of boiled lymphocytes and platelets, the $6 \mathrm{KPGF}_{1 \alpha}$ peak was undetectable, nor was the peak discernible when $\left[{ }^{14} \mathrm{C}\right] \mathrm{AA}$ was incubated with lymphocytes alone. Lymphocytes prelabeled with $\left[{ }^{14} \mathrm{C}\right] \mathrm{AA}$ failed to form any discernible eicosanoid peak including the $6 \mathrm{KPGF}_{1 \alpha}$ when stimulated with PHA. Prelabeled

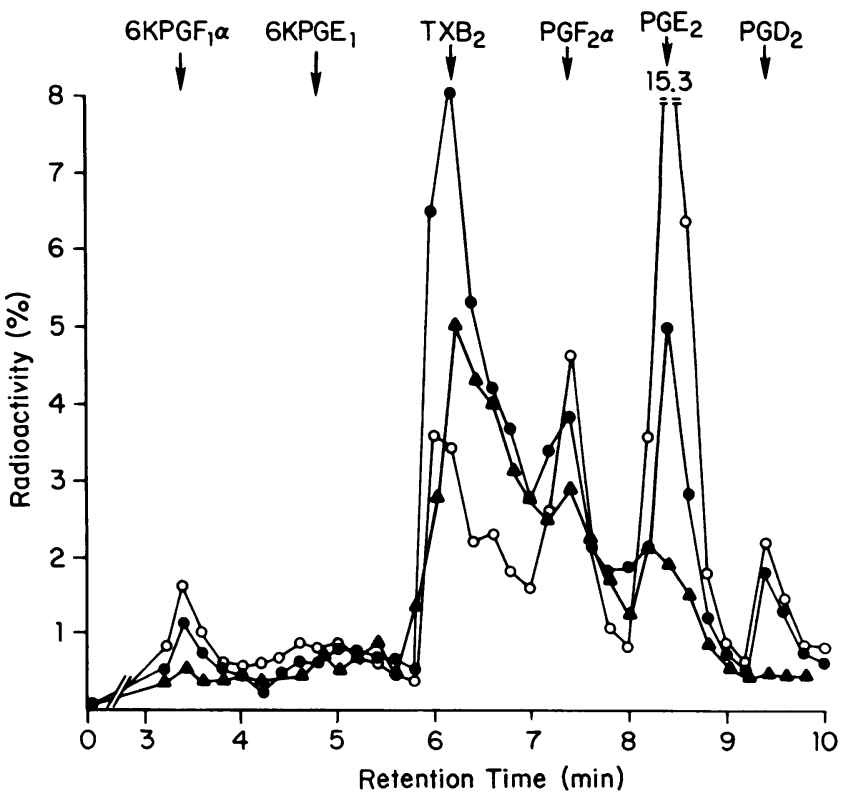

Figure 1. Separation of $6 \mathrm{KPGF}_{1 \alpha}$ and other prostanoids by reversephase HPLC using the initial isocratic solvent system which excluded HHT, 12-HETE, and AA (see Methods). The arrows refer to the relative retention time of each eicosanoid as determined with tritiated standards. The eicosanoid profile produced by lymphocytes treated with $\left[{ }^{14} \mathrm{C}\right] \mathrm{AA}(\Lambda)$, by a mixture of platelets and lymphocytes incubated with $\left[{ }^{14} \mathrm{C}\right] \mathrm{AA}(\bullet)$, and when platelets were pretreated with 1-BI before the addition of lymphocytes and $\left[{ }^{14} \mathrm{C}\right] \mathrm{AA}(\mathrm{O})$. Percentages of radioactivity were calculated on the basis of total prostanoids excluding HHT, HETEs, and AA. 
Table I. Eicosanoid Generation by Platelet, Lymphocyte, and Mixed Platelet-Lymphocyte Preparations

\begin{tabular}{|c|c|c|c|c|c|c|c|}
\hline \multirow[b]{2}{*}{ Agonists } & \multicolumn{7}{|c|}{ Eicosanoids } \\
\hline & $6 \mathrm{KPGF}_{\alpha}$ & $\mathrm{TXB}_{2}$ & $\mathrm{PGF}_{2 \boldsymbol{m}}$ & $\mathrm{PGE}_{2}$ & $\mathrm{PGD}_{2}$ & 12-HETE & HHT \\
\hline & $\%$ & $\%$ & $\%$ & $\%$ & \% & $\%$ & \% \\
\hline \multicolumn{8}{|l|}{ Ionophore $(10 \mu \mathrm{M})$} \\
\hline${ }^{*} \mathrm{~L}$ & 0 & 7.1 & 0 & 1.3 & 0 & 13.3 & 6.3 \\
\hline$* \mathbf{P}$ & 0 & 13.7 & 0 & 1.9 & 0 & 14.0 & 6.1 \\
\hline${ }^{*} \mathbf{P}+1-\mathrm{BI}$ & 0 & 2.1 & 2.4 & 11.5 & 13.2 & 13.0 & 3.0 \\
\hline${ }^{*} \mathbf{P}+\mathrm{L}$ & 1.2 & 10.0 & 0 & 0 & 0 & 13.7 & 7.9 \\
\hline${ }^{*} \mathbf{P}+\mathrm{L}+1-\mathrm{BI}$ & 2.0 & 2.5 & 3.5 & 5.9 & 2.7 & 7.8 & 2.0 \\
\hline \multicolumn{8}{|c|}{ Thrombin $(0.5 \mathrm{U} / \mathrm{ml})$} \\
\hline$* \mathbf{P}$ & 0 & 8.3 & 0 & 1.8 & 1.2 & 12.8 & 5.9 \\
\hline${ }^{*} \mathrm{P}+1-\mathrm{BI}$ & 0 & 2.7 & 3.3 & 4.7 & 5.2 & 7.5 & 1.6 \\
\hline$* P+L$ & 1.0 & 9.3 & 0 & 1.3 & 1.2 & 10.3 & 7.4 \\
\hline${ }^{*} P+L+1-B I$ & 1.5 & 2.4 & 4.2 & 6.5 & 5.0 & 8.0 & 3.1 \\
\hline \multicolumn{8}{|l|}{ Collagen $(10 \mu \mathrm{g} / \mathrm{ml})$} \\
\hline${ }^{*} \mathbf{P}$ & 0 & 4.3 & 0 & 2.1 & 1.6 & 3.2 & 2.6 \\
\hline${ }^{*} \mathrm{P}+1-\mathrm{BI}$ & 0 & 1.8 & 1.9 & 2.1 & 2.3 & 4.9 & 3.0 \\
\hline${ }^{*} \mathrm{P}+\mathrm{L}$ & 1.3 & 4.6 & 0 & 1.4 & 0 & 3.2 & 2.6 \\
\hline${ }^{*} \mathbf{P}+\mathbf{L}+1-\mathbf{B I}$ & 2.0 & 4.0 & 4.2 & 6.1 & 4.2 & 4.5 & 2.6 \\
\hline
\end{tabular}

Experimental details are described in the Methods. After the incubation of cell preparations with each agonist, reaction was terminated and eicosanoids were extracted and analyzed by reverse-phase HPLC. Percentage of each eicosanoid refers to the percentage at the peak point. "0" denotes no discernible peak. ${ }^{*} \mathrm{~L}$ and ${ }^{*} \mathrm{P}$ denote lymphocytes and platelets prelabeled with $\left[{ }^{14} \mathrm{C}\right] \mathrm{AA}$, respectively. $\mathrm{L}$ denotes aspirin-treated unlabeled lymphocytes.

lymphocytes also did not generate $6 \mathrm{KPGF}_{1 \alpha}$ when treated with ionophore, although $\mathrm{TXB}_{2}$, HHT, and 12-HETE peaks were apparent (Table I). When the prelabeled platelets were suspended together with aspirin-treated lymphocyte preparations and stimulated with ionophore, thrombin, and collagen, $6 \mathrm{KPGF}_{1 \alpha}$ peak was detected and was enhanced by treating platelets with 1-BI (Table I). $\mathrm{PGE}_{2}, \mathrm{PGF}_{2 \alpha}$, and $\mathrm{PGD}_{2}$ peaks were also increased by treating the cells with the TX synthase inhibitor. The 12HETE peak was discernible in all the cell preparations, including ionophore-treated lymphocytes prelabeled with $\left[{ }^{14} \mathrm{C}\right] \mathrm{AA}$. The eicosanoid profile of ionophore-treated lymphocytes was similar to that of ionophore-treated platelets, which was consistent with the view that the eicosanoids released in the stimulated lymphocyte preparation were contributed primarily by the contaminating platelets.

In separate experiments, HPLC fractions corresponding to the $6 \mathrm{KPGF}_{1 \alpha}$ peak were collected and the $6 \mathrm{KPGF}_{1 \alpha}$ content was measured by RIA. Results are shown in Fig. 2. Lymphocyte preparations $\left(10^{7}\right.$ cells $/ \mathrm{ml}$ ) produced $0.18 \mathrm{ng}$ of $6 \mathrm{KPGF}_{1 \alpha}$ (mean of three experiments) when incubated with $10 \mu \mathrm{M}$ AA for $3 \mathrm{~min}$ at $37^{\circ} \mathrm{C}$ (Fig. $2 \mathrm{~A}$ ). Lymphocytes incubated with platelets in the absence of exogenous AA did not produce measurable quantities of $6 \mathrm{KPGF}_{1 \alpha}$, yet in the presence of $10 \mu \mathrm{M} \mathrm{AA}$, lymphocyte and platelet mixtures produced an average of $1.39 \mathrm{ng}$ of $6 \mathrm{KPGF}_{1 \alpha}$ (almost an eightfold increase over lymphocytes alone) (Fig. 2 $B) .6 \mathrm{KPGF}_{1 \alpha}$ production was further enhanced by pretreating platelets with $5 \mathrm{mM}$ 1-BI (Fig. $2 C$ ). These results suggest that lymphocytes do not metabolize AA directly, but that they possess sufficient $\mathrm{PGI}_{2}$ synthase activity to synthesize $\mathrm{PGI}_{2}$ from $\mathrm{PGH}_{2}$. To test this hypothesis, $5 \mu \mathrm{M}$ ultrapurified $\mathrm{PGH}_{2}$ was incubated with washed lymphocytes. The supernatant was applied to HPLC, and 6KPGF ${ }_{1 \alpha}$ content in the HPLC fractions was measured by RIA. Significant quantities of $6 \mathrm{KPGF}_{1 \alpha}$ were synthesized (Fig. $2 \mathrm{D}$ ). $\mathrm{PGH}_{2}$ incubated in buffer alone under similar

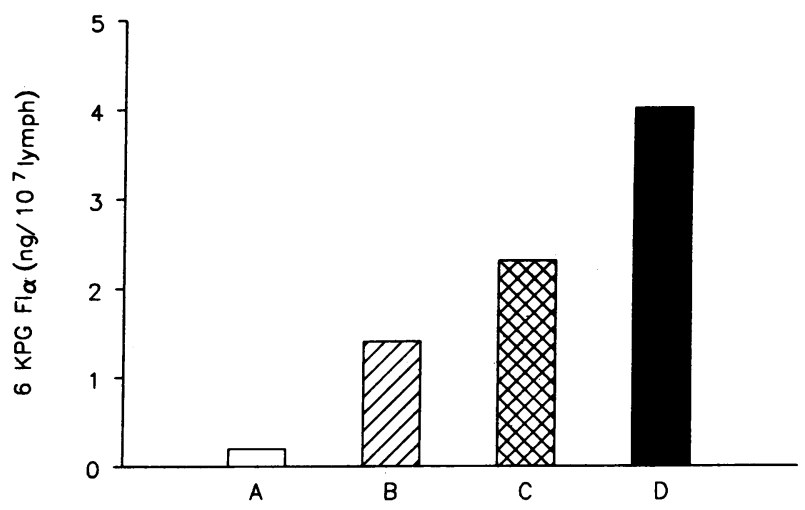

Figure 2. Production of $6 \mathrm{KPGF}_{1 \alpha}$ by $(A)$ lymphocyte preparations treated with $10 \mu \mathrm{M} A \mathrm{~A},(B)$ mixed lymphocyte and platelet preparations treated with $10 \mu \mathrm{M}$ AA in the absence of $1-\mathrm{BI},(C)$ mixed lymphocyte and platelet preparations in the presence of 1-BI, and $(D)$ lymphocyte preparations treated with $5 \mu \mathrm{M}$ ultrapurified $\mathrm{PGH}_{2}$. In each experiment, after treatment with $\mathrm{AA}$, the supernatant was collected and the prostanoids were extracted and separated by reversephase HPLC. The $6 \mathrm{KPGF}_{1 \alpha}$ fractions were pooled and their $6 \mathrm{KPGF}_{1 \alpha}$ content was measured by RIA. The lymphocyte concentration in each experiment was $10^{7} / \mathrm{ml}$ and the platelet concentration was $3 \times 10^{8} / \mathrm{ml}$. The results represent mean values of two to five experiments. 
experimental conditions was not spontaneously hydrolyzed to $6 \mathrm{KPGF}_{1 \alpha}$, although it did convert to $\mathrm{PGE}_{2}$ and $\mathrm{PGF}_{2 \alpha}$. The effect of ionophore on $\mathrm{PGI}_{2}$ synthesis by the mixed cell preparations was evaluated by HPLC separation followed by RIA measurement. Washed lymphocytes were incubated with platelets and then $10 \mu \mathrm{M}$ ionophore was added. The $6 \mathrm{KPGF}_{1 \alpha}$ content was comparable to that produced by the cell mixture treated with AA (mean of two experiments was $1.21 \mathrm{ng}$ ). Synthesis of $6 \mathrm{KPGF}_{1 \alpha}$ by washed buffy-coat cells in response to platelet stimuli such as thrombin, collagen, and AA was then determined. Washed buffy-coat cells prepared from $4.5 \mathrm{ml}$ of citrated venous blood were incubated with $10 \mu \mathrm{M} \mathrm{AA}, 10 \mu \mathrm{g} / \mathrm{ml}$ collagen, or $0.1 \mathrm{U} / \mathrm{ml}$ thrombin at $37^{\circ} \mathrm{C}$ for $3 \mathrm{~min}$. The reaction was terminated by rapid centrifugation, the supernatant was collected, and its $6 \mathrm{KPGF}_{1 \alpha}$ concentration was measured by RIA. Mean $6 \mathrm{KPGF}_{1 \alpha}$ values from the $\mathrm{AA}$, thrombin, and collagen-stimulated preparations were $3.42,1.42$, and $1.68 \mathrm{ng}$, respectively, whereas the vehicle-treated controls had no measurable $6 \mathrm{KPGF}_{1 \alpha}$.

To evaluate the physiologic significance of these observations, we compared the platelet reactivity with three physiologic agonists in the presence and absence of lymphocytes (Fig. 3). Addition of lymphocytes alone to platelets without accompanied agonists did not alter light transmission. Neither did treatment of lymphocytes with the agonists cause lymphocyte aggregation or alter light transmission. By contrast, when lymphocytes were mixed with platelet suspensions and an agonist (AA, thrombin, or collagen) was added, platelet aggregation and $\left[{ }^{14} \mathrm{C}\right]$ serotonin release were inhibited (Fig. 3). The degree of inhibition was related to the lymphocyte concentrations added to the platelet suspensions (Fig. 4). To determine whether the inhibiting effect of lymphocytes was primarily due to $\mathrm{PGI}_{2}$ generation, we measured the $6 \mathrm{KPGF}_{1 \alpha}$ content in the aggregometer supernatant by bioassay and RIA. Platelets $\left(3 \times 10^{8} / \mathrm{ml}\right)$ and lymphocytes $(1$ $\times 10^{7} / \mathrm{ml}$ ) were co-incubated by $37^{\circ} \mathrm{C}$ in an aggregometer cuvette for $1 \mathrm{~min}$ followed by addition of $10 \mu \mathrm{g} / \mathrm{ml}$ collagen. Platelet aggregation was continuously recorded. At the end of $5 \mathrm{~min}$, the cuvette was removed from the aggregometer, the stirring bar was removed, and the sample was rapidly spun at $13,000 \mathrm{~g}$ to remove the cells. The $6 \mathrm{KPGF}_{1 \alpha}$ content in the supernatant was determined by RIA. The antiaggregatory activity of $\mathrm{PGI}_{2}$ in the sample was determined by relating the percent inhibition of platelet aggregation to a calibration curve established in each experiment. The mean $\mathrm{PGI}_{2}$ antiaggregating activity from three experiments was $1.56 \mathrm{ng} / \mathrm{mi}$, whereas the $6 \mathrm{KPGF}_{1 \alpha}$ content measured by RIA was $1.48 \mathrm{ng} / \mathrm{ml}$, hence, similar values were obtained by two very different assay methods.

\section{Discussion}

Our data support the hypothesis that $\mathrm{PGI}_{2}$ is produced through the interaction of blood platelets and lymphocytes. Three separate assays (i.e., HPLC, RIA, and bioassay) have corroborated the conclusion that these two cells can cooperate to produce a quantity of $\mathrm{PGI}_{2}$ sufficient to inhibit platelet aggregation and release reaction. That the active component is indeed $\mathrm{PGI}_{2}$ is supported by two lines of evidence. First was the support by the RIA data on the HPLC-purified 6KPGF $1 \alpha$, which in other studies in our laboratory has correlated well with values obtained by
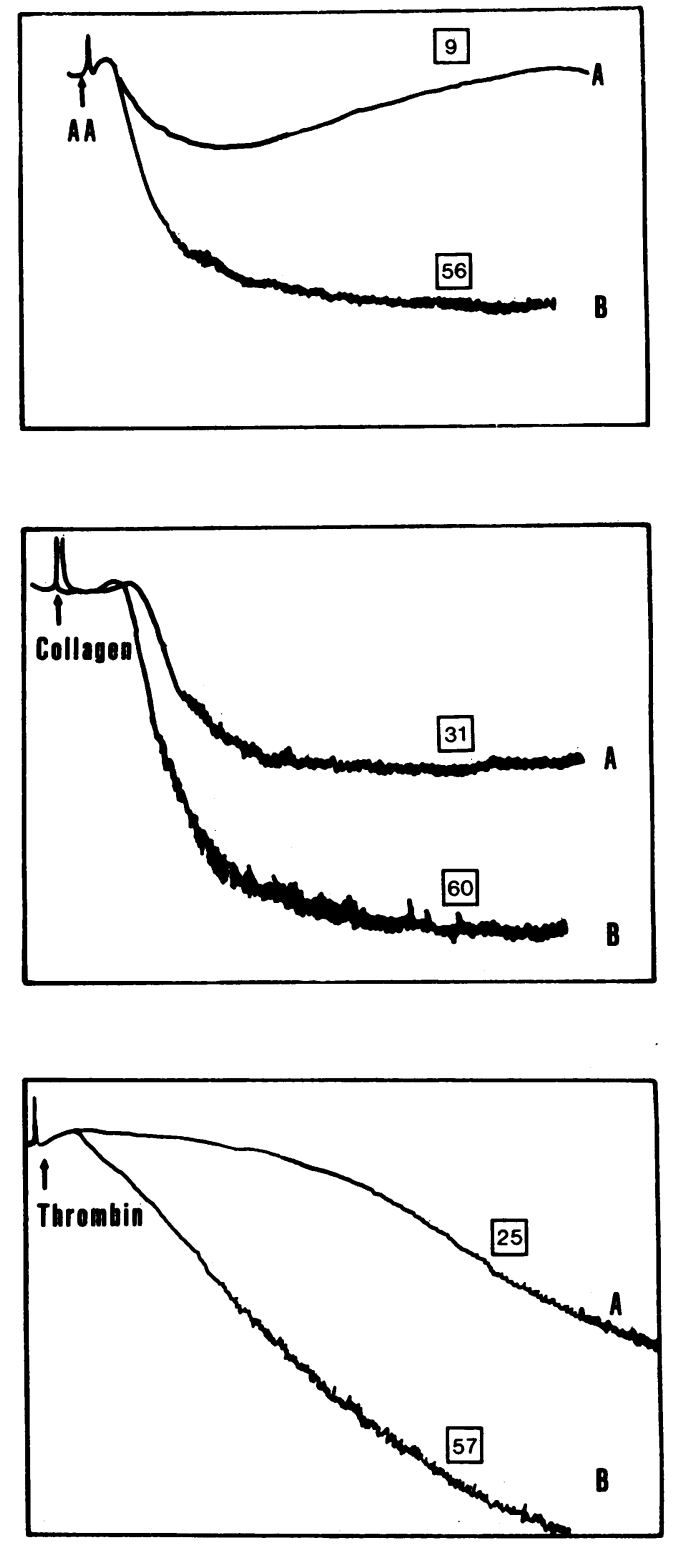

Figure 3. Platelet aggregation induced by $10 \mu \mathrm{M}$ AA, $10 \mu \mathrm{g} / \mathrm{ml}$ collagen, and $0.1 \mathrm{U} / \mathrm{ml}$ thrombin in the presence (tracing $A$ ) and absence (tracing $B$ ) of lymphocytes. The results are representative of 10 reproducible experiments. The platelet concentration in the washed platelet suspension was $3 \times 10^{8} / \mathrm{ml}$, whereas the lymphocyte concentration was $1 \times 10^{7} / \mathrm{ml}$. Platelet-release reaction measured by $\left[{ }^{14} \mathrm{C}\right]$ serotonin release was performed separately under similar experimental conditions. The number indicated in each box at the top of the aggregation tracing denotes the mean percentage of serotonin release of two experiments done in duplicate.

gas chromatography-mass spectrometry (13). The second line of evidence is afforded by the close approximation of the $6 \mathrm{KPGF}_{1 \alpha}$ values obtained by the HPLC-RIA and the bioassay.

The notion that lymphocyte $\mathrm{PGI}_{2}$ production depends on platelet-generated $\mathrm{PGH}_{2}$ is consistent with several of our observations. For instance, $\mathrm{PGI}_{2}$ production by the platelet-lymphocyte mixture requires the initial activation of platelets. Pretreatment of platelets with a cyclooxygenase inhibitor abolishes lym- 


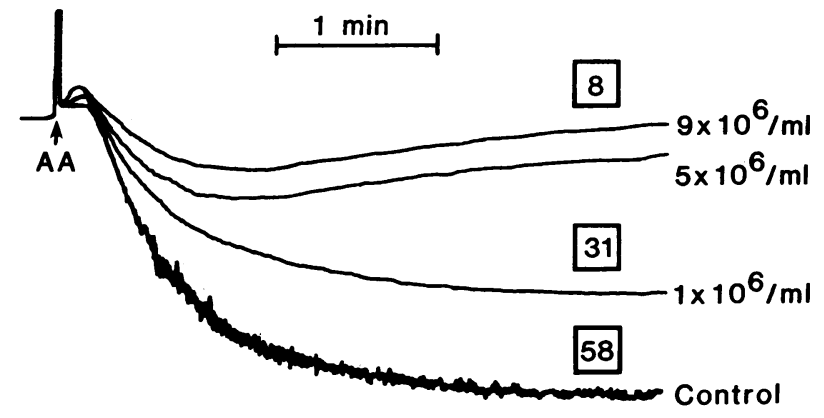

Figure 4. Inhibition of platelet aggregation by various concentrations of lymphocytes. The platelet concentration was fixed at $3 \times 10^{8} / \mathrm{ml}$ The lymphocyte concentrations are indicated with each tracing. To correct the influence of lymphocyte mass on light transmission, the PPP cuvette contained the same lymphocyte concentration as the PRP cuvette. Platelet aggregation was induced with $10 \mu \mathrm{M}$ AA. Serotonin release experiments were performed separately under similar conditions. An identical AA concentration was employed to induce release reaction. The number shown in each box denotes mean percentage of $\left[{ }^{14} \mathrm{C}\right]$ serotonin release of two experiments done in duplicate.

phocyte $\mathrm{PGI}_{2}$ production, whereas blocking platelet TX synthase activity with a specific inhibitor enhances it. $\mathrm{PGI}_{2}$ is formed when aspirin-treated lymphocytes are incubated with radiolabeled platelets and then stimulated with calcium ionophore, thrombin, or collagen, whereas lymphocytes alone fail to produce $\mathrm{PGI}_{2}$ despite stimulation with PHA and ionophore. Direct evidence was provided in this study by demonstrating a significant production of $6 \mathrm{KPGF}_{1 \alpha}$ by washed lymphocytes treated with a highly purified $\mathrm{PGH}_{2}$ preparation. Availability of this pure $\mathrm{PGH}_{2}$ preparation permits us to document unequivocally that lymphocytes possess sufficient $\mathrm{PGI}_{2}$ synthase enzyme to metabolize $\mathrm{PGH}_{2}$ into biologically active $\mathrm{PGI}_{2}$.

We have compared the major metabolites in lymphocyte, platelet, and lymphocyte-platelet preparations stimulated with the calcium ionophore. Except for the presence of $6 \mathrm{KPGF}_{1 \alpha}$, which is formed in the platelet-lymphocyte mixture only, major metabolites generated in these three cell preparations are similar. These data, particularly the approximation of 12-HETE production in all three preparations, indicate that these metabolites are generated by platelets. Measurement of 12-HETE is useful for assessing monocyte contamination because blood monocytes do not synthesize 12-HETE. A significant monocyte contamination should lower the 12-HETE content in the lymphocyte preparation. Based on the eicosanoid profile and our microscopic data, we conclude that the eicosanoids generated by lymphocyte preparation are derived from platelet and not from monocyte contaminants. The contaminated platelet concentration $\left(10^{6} /\right.$ $\mathrm{ml}$ ), however, is too low to provide lymphocytes with sufficient $\mathrm{PGH}_{2}$ to synthesize a detectable quantity of $\mathrm{PGI}_{2}$. The eicosanoid data shown in Table I also indicate that both calcium ionophore and thrombin produce a similar eicosanoid profile when added to the lymphocyte-platelet mixture, whereas collagen is a weaker stimulator of AA metabolism. Blocking of platelet TX synthase in all these preparations leads to formation of a discernible quantity of $\mathrm{PGD}_{2}$ and $\mathrm{PGE}_{2}$. These compounds may further enhance the antiplatelet aggregating effect of $\mathrm{PGI}_{2}$ produced in the same mixture.
Treatment of platelets with physiologic agonists in the presence of lymphocytes triggers the production of sufficient $\mathbf{P G I}_{2}$ to inhibit platelet aggregation. Changes in platelet aggregation tracings are not merely due to the masses of lymphocytes, which may impede the light transmission, because $(a)$ the inhibiting effect was evident when a separate platelet function marker (i.e., $\left[{ }^{14} \mathrm{C}\right]$ serotonin release) was used, $(b)$ the inhibiting effect was related to the concentration of the agonist added without changing lymphocyte and platelet concentrations and therefore should not be due to an artificial effect of lymphocyte masses, (c) the antiplatelet effect correlated well with the quantity of $\mathrm{PGI}_{2}$ produced as measured by both the bioassay and the RIA, and $(d)$ each experiment had a carefully standardized internal blank control. Inhibition of platelet function depends on the lymphocyte concentration. In fact, even $10^{6}$ lymphocytes per millimeter of platelet preparation that contained $3 \times 10^{8}$ platelets exhibited appreciable platelet inhibition.

Our observations resolve the mystery of why serum $6 \mathrm{KPGF}_{1 \alpha}$ levels are higher than the plasma levels. Both the buffy-coat cells and the platelet-lymphocyte mixture experiments indicate that during blood coagulation, generation of thrombin leads to platelet activation and initiation of AA metabolism. Platelet-derived $\mathrm{PGH}_{2}$ is released and utilized by lymphocytes to form $\mathrm{PGI}_{2}$. It is unclear whether this process requires direct cell-to-cell contact. Nevertheless, it may represent an important mechanism whereby $\mathrm{PGI}_{2}$ can be effectively produced without relying on a single cell source. Platelets appear to function as a donor of $\mathrm{PGH}_{2}$ for several other cells to synthesize $\mathrm{PGI}_{2}$. For example, we have recently shown that $\mathrm{PGI}_{2}$ is produced by subendothelial smooth muscle cells through platelet donation of $\mathrm{PGH}_{2}$ (14). Platelets are also donors of $\mathrm{PGH}_{2}$ for cultured endothelial cells to synthesize $\mathrm{PGI}_{2}$ (15-17). Although the individual quantity of $\mathrm{PGI}_{2}$ produced by each cell-cell interaction is small, summation of the total $\mathrm{PGI}_{2}$ produced will have a powerful biological activity. This may represent a major mechanism whereby $\mathrm{PGI}_{2}$ acts as an effective autocoid in modulating hemostasis, inflammation, and immune responses.

\section{Acknowledgments}

We are grateful to Dr. Cora Bucana for performing the scanning electron microscope work. The skillful technical assistance of Ms. Nyena Vijjeswarapu and Mr. T. Layne Crowe and secretarial assistance of Ms. Nancy Fernandez are gratefully acknowledged.

This work was supported in part by a program project grant from the National Institutes of Health (PO1 NS-18494) and a Research Career Development Award (K04 NS-00873) to Dr. Hall.

\section{References}

1. Parker, C. W., W. F. Stenson, M. G. Huber, and J. P. Kelly. 1979. Formation of $\mathrm{TXB}_{2}$ and hydroxyarachidonic acids in purified human lymphocytes in the presence and absence of PHA. J. Immunol. 122: 1572-1577.

2. Goldyne, M. E., and J. D. Stobo. 1982. Human monocytes synthesize eicosanoids from T lymphocyte-derived arachidonic acid. Prostaglandins. 24:623-630.

3. Defreyn, G., H. Deckmyn, and J. Vermylen. 1982. A thromboxane synthase inhibitor reorients endoperoxide metabolism in whole blood towards $\mathrm{PGI}_{2}$ and $\mathrm{PGE}_{2}$. Thromb. Res. 26:389-400. 
4. Pedersen, A. K., M. L. Watson, and G. A. FitzGerald. 1983. Inhibition of thromboxane biosynthesis in serum: limitations of the measurement of immunoreactive 6-keto-PGF $F_{1 \alpha}$. Thromb. Res. 33:99-103.

5. Zulak, I. M., M. L. Puttemans, A. B. Schilling, E. R. Hall, and D. L. Venton. 1986. A fast non-destructive purification scheme for $\mathbf{P G H}_{2}$ using a non-aqueous bond-phase, HPLC system. Anal. Biochem. 154: 152-161.

6. Boyum, A. 1976. Isolation of lymphocytes, granulocytes and macrophages. Scand. J: Immunol. Suppl. 5:9-19.

7. Walsh, P. N. 1972. Albumin density gradient separation and washing of platelets and the study of coagulant activities. Br. J. Haematol. 22:205-217.

8. Hall, E. R., W. Tuan, and D. L. Venton. 1986. Production of platelet thromboxane $A_{2}$ inactivates purified human platelet thromboxane synthase. Biochem. J. 233:637-641.

9. Wu, K. K., E. R. Hall, E. C. Rossi, and A. C. Papp. 1985. Serum prostacyclin binding defects in thrombotic thrombocytopenic purpura. J. Clin. Invest. 75:168-174.

10. Born, G. V. R. 1962. Aggregation of blood platelets by adenosine diphosphate and its reversal. Nature (Lond.). 194:927-929.

11. Chen, Y. C., E. R. Hall, and K. K. Wu. 1981. Accelerated $\mathbf{P G I}_{2}$ degradation in thrombotic thrombocytopenic purpura. Lancet. ii:267269.

12. Weiss, H. J., T. Tschopp, H. Brand, and J. Rogers. 1974. Studies on platelet 5-hydroxytryptamine (serotonin) in patients with storagepool disease and albinism. J. Clin. Invest. 54:421-425.

13. Hall, E. R., A. C. Papp, W. E. Seifert, and K. K. Wu. 1986. Stimulation of endothelial cell prostacyclin formation by interleukin 2 . Lymphokine Res. 5:87-96.

14. Papp, A. C., L. Crowe, L. C. Pettigrew, and K. K. Wu. 1986. Production of eicosanoids by deendothelialized rabbit aorta. Interaction between platelets and vascular wall in the synthesis of prostacyclin. Thromb. Res. 42:549-556.

15. Marcus, A. J., B. B. Weksler, E. A. Jaffe, and M. J. Broekman. 1980. Synthesis of prostacyclin from platelet-derived endoperoxides by cultured human endothelial cells. J. Clin. Invest. 66:979-986.

16. Needleman, P. A., A. Wyche, and A. Raz. 1979. Platelet and blood vessel arachidonate metabolism and interactions. J. Clin. Invest. 63:345-349.

17. Schafer, A. I., D. D. Crawford, and M. A. Gimbrone. 1984. Unidirectional transfer of prostaglandin endoperoxides between platelets and endothelial cells. J. Clin. Invest. 73:1105-1112. 